\title{
Tangential Learning of Mental Illness by Using Procedural Content Generation in Video Game
}

\author{
Chandra Limiarja ${ }^{1}$, Yulyani Arifin ${ }^{2}$ \\ ${ }^{1}$ Computer Science Department, School of Computer Science, Bina Nusantara University, Jakarta, Indonesia \\ 11480 \\ ${ }^{2}$ Computer Science Department, School of Computer Science, Bina Nusantara University, Jakarta, Indonesia \\ 11480, yulyaniarifin@binus.ac.id
}

\begin{abstract}
The main purpose of this research is to create a video game with a limited amount of resource (such as time and developer), while also creating a game that promotes Tangential learning in order to raise an awareness towards Mental Illness in a fun and enjoyable experience. The game will use Procedural Content Generation to minimize the amount of resource needed and incorporating the theme that will be beneficial to learn something about Mental Illness. A game that were made using Procedural Content Generation, but there are not yet a game that combines this with a Tangential learning element of Mental Illness. This thesis focuses on the development of the game from the start to finish and conduct game test to see how effective it is as an enjoyable game that indirectly give someone new information about Mental Illness. This testing is done by doing a post-test survey to measure the player's experience, whether they learned something new or not and whether their experience is enjoyable or not. Based on the survey, the majority of players answered that they have learned something new and/or received the message of the game, and they rated their experience as good.
\end{abstract}

Key words : Game,Mental Illness, Procedural Content Generation, Tangential Learning,

\section{INTRODUCTION}

With the rise in popularity of indie game developers, there are two points that we can focus these two points[1]. First, there is a challenge that indie game developers face in developing their game where they need to compete in the nowadays market with their limited resource due to their usual small team. Procedural Content Generation is a method that can be used as a solution to deal with this challenge. According to Alba Almato, this procedurally generated content can be used to automatically or semi-automatically create various aspects in a game, essentially in designing a level or in the creation of the gameplay aspect or the contents of the game [2]. Second, in this rise of popularity, we need to be able to utilize video games in its fullest potential, and not just in the economical standpoint. The importance of the game playing is increasing enormously. The games must be designed and developed keeping the objectives and goals that must be achieved [3].Video game is a very powerful media that can be used to deliver a message to a lot of people through their experience of playing the game [4].

With a method called Tangential Learning, players will be able to self-taught themselves about a topic in a media that they enjoyed Brown, T., Rivera,. The main topic that will be used in this research project is Mental Illness. With the data from National Alliance of Mental Health in the US, we can find out that one in five college students are suffering mental illness. This affects their grades and make them more likely to drop out from their study (Strickland, 2017). This is a very serious issue to be represented throughout the media.

\section{RESEARCH METHODOLOGY}

The model used in the research methodology is the Waterfall model, due to the straightforwardness of the game design project [5]. The planning stage is done by doing data collecting, which is done through literature study of related papers and questionnaire directed towards gamers in general and game developers. The results are analyzed in the analysis stage, along with doing requirement analysis through interview with an expert in adult psychology, Ms. RiantiWidiastuti, M. Psi. The conclusion from the analysis then used in the design stage to design the game and assets. The game is programmed in Unity in the implementation stage and tested and evaluated in the system stage[6].

\section{RESULTS AND DISCUSSION}

Based on the result of the questionnaire done by the players that have tested the game, the game has been successful in delivering a message to raise an awareness towards mental illness and taught them something new regarding the topic. The game also is enjoyable and fun through their rating of the game. The suggestions for the future works are to implement new type of mental illness topic in the game, expand to a new platform, and more challenge and unlockable such as an achievement system. 


\section{CONCLUSION AND SUGGESTION}

Based on the survey, the majority of players answered that they have learned something new and/or received the message of the game, and they rated their experience as good.

Based on the analysis result and the testing result of the game Dreamscann, the following are the conclusion drawn:

1.Overall, by using a limited resource and content, the game DreamScann is a good game application based on the result of the questionnaire directed to the testers, in evaluating User Application evaluation, as well as Expert evaluation, User Interface, and Multimedia evaluation.

2.The game DreamScann has successfully indirectly taught players that have played this game based on the survey done by the testers. With the most frequent things that player said they have learned about "Mental Health", "Mental Illness", "Mental Problem", and "How to Help".

3.The game DreamScann gives entertainment towards the player while also gives a message to raise awareness regarding mental illness and teach the players indirectly how to help others around them that struggle with it.

\section{REFERENCES}

[1] E.Adams,Fundamentals of Game Design Third Edition, Berkeley, California, USA: New Riders, 2013

[2] A. Amato. Procedural Content Generation in the Game Industry. In the bookGame Dynamics(Editor: O. Korn), Springer International Publishing, 2017.

[3] S.Bhanu, J.K.R. Sastry, B. S. Devi, V. C. Prakash, "Career Guidance through TIC-TAC-TOE Game,"International Journal of Emerging Trends in Engineering Research, vol. 7 no. 6, pp. 25-31, 2019.

[4] A. D. M. Africa, G. Ching, K. Go, R. Evidente, and J. Uy, "A Comprehensive Study on Application Development Software Systems, "International Journal of Emerging Trends in Engineering Research, vol. 7 no. 8, pp 99-103, 2019.

[5] J.L.Whitten and L.D. Bentley,Systems Analysis and Design Methods 7th Edition. New York, NY, USA: McGraw-Hill Irwin, 2007.

[6] W. Goldstone, Unity 3.x Game Development Essentials, Birmingham, UK: Packt Publishing Ltd. 2011. 